\title{
MOTIVAÇÕES DE ECOEMPREENDEDORES: ESTUDO DE CASOS MÚLTIPLOS EM CURITIBA, PARANÁ
}

Vivien Kaniak $^{1}$

Rivanda Meira Teixeira ${ }^{1}$

${ }^{1}$ Universidade Federal do Paraná - Campus Curitiba-PR - Setor de Ciências Sociais Aplicadas 


\section{MOTIVAÇÕES DE ECOEMPREENDEDORES: ESTUDO DE CASOS MÚLTIPLOS EM CURITIBA, PARANÁ}

Resumo: Ecoempreendedores assumem papel de destaque como a figura central para encontrar soluções para a degradação ambiental diferentemente dos empreendedores de motivação puramente econômica típicos das décadas anteriores. O objetivo central desta pesquisa foi analisar as motivações de ecoempreendedores com base nas tipologias de Walley \& Taylor (2002). A metodologia utilizada foi a qualitativa e exploratória e a estratégia de pesquisa foi o estudo de casos múltiplos. Participaram do estudo cinco ecoempreendedores da região metropolitana de Curitiba-PR que foram entrevistados com adoção de roteiro semiestruturado. Além dessas evidências foi utilizada a triangulação com observação não participante e análise documental. Os resultados apontam que os ecoempreendedores entrevistados tem por motivação o lucro ao mesmo tempo que possuem forte direcionamento ecológico na gestão de seus negócios. No geral eles tiveram influência de familiares ou amigos para montar o empreendimento e o utilizam para manutenção de seu estilo de vida.

Palavras-chave: Ecoempreendedores. Motivações. Tipologias.

\section{Introdução}

No cenário global atual em que são buscadas alternativas para preservação da natureza, a criação de negócios sustentáveis dá suporte ao crescimento da economia além de resultar na melhora da qualidade de vida e redução de riscos ecológicos (ANUP; RIJAL; SAPKOTA, 2015).

O Empreendedorismo sustentável também é um tema de destaque em pesquisa nos últimos anos com aspectos amplos que abrangem questões organizacionais, financeiras, políticas, ecológicas, entre outras (ISAAK, 2002; KOE; MAJID, 2014; MIESZAJKINA, 2016; PASTAKIA, 1998; SCHALTEGGER, 2002). Entretanto é importante salientar que empreendedorismo sustentável não é sinônimo de ecoempreendedorismo, uma vez que o último objetiva atuar em questões ecológicas, enquanto o primeiro é muito mais amplo e engloba o sustento de comunidades e desenvolvimento para indivíduos e sociedade (SHEPHERD; PATZELT, 2011).

Embora a literatura sobre pequenas empresas atuando no setor verde tenha aumentado ainda existem poucos estudos sobre quem é o ecoempreendedor por trás destas empresas (BORGES et al., 2013; KIRKWOOD; WALTON, 2010; SHEPHERD; PATZELT, 2011; WALLEY; TAYLOR, 2002). Por este motivo, estudar o papel do pequeno empreendedor e seu perfil é crítico promover um futuro mais sustentável (BUDEANU et al., 2016). Nas pesquisas existentes os empreendedores verdes têm sido caracterizados de acordo com certas tipologias que, por sua vez, são reconhecidos através de suas motivações para iniciar ou se manter no negócio (GIBBS, 2009; SWAN; MORGAN, 2016).
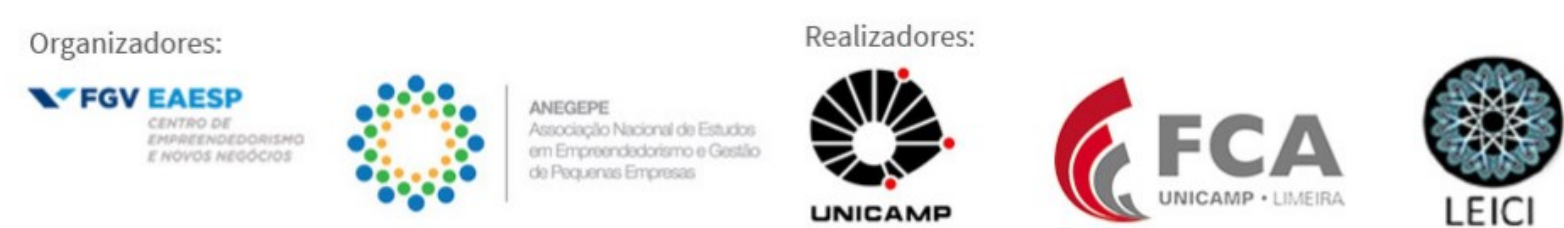
Neste contexto, o ecoempreendedor assume um papel de destaque como a figura central para encontrar soluções para a degradação ambiental (PARRISH, 2010; SHEPHERD; PATZELT, 2011; YORK; VENKATARAMAN, 2010), diferentemente dos empreendedores de motivação puramente econômica típicos das décadas anteriores.

Dado a importância do tema, o objetivo geral deste estudo é investigar as motivações dos ecoempreendedores baseado na tipologia de Walley \& Taylor (2002). Especificamente busca caracterizar as empresas sustentáveis, delinear o perfil dos ecoempreendedores e identificar suas motivações para criar negócios ecologicamente sustentáveis.

Espera-se que a pesquisa traga contribuições pragmáticas para a temática trazendo luz sobre os fatores que motivam os ecoempreendedores a criarem seus negócios. Os resultados obtidos podem ser utilizados tanto para discussões acadêmicas quanto para oferecer subsídios para que se criem e promovam estratégias de desenvolvimento do eco negócios; para embasar e impulsionar novos empreendedores preocupados em criar uma sociedade mais sustentável.

\section{Empreendedorismo Sustentável e Ecoempreendedorismo}

Historicamente o conceito de empreendedorismo sustentável surgiu em 1987 na Conferência de Brundtland e está ligado a criação de empreendimentos baseados nas três dimensões de sustentabilidade: a social, ambiental e econômica (BORGES et al., 2013; GIBBS, 2009; THOMPSON, 1999; TILLEY; YOUNG, 2009).

Entretanto a definição de empreendedorismo sustentável vai além e envolve fatores mais complexos tal qual apresentado por Shepherd \& Patzelt (2011, p.142):

"Empreendedorismo sustentável tem foco na preservação da natureza, suporte a vida e a comunidade na busca de oportunidades percebidas para trazer a existência futuros produtos, processos, e serviços para o ganho, onde ganho é amplamente construído para incluir ganhos econômicos e não-econômicos para indivíduos, a economia e a sociedade".

De acordo com pesquisadores como Schaltegger \& Wagner (2011) a ideia de empreendedorismo sustentável foi se modificando de modo a englobar não somente o desenvolvimento das organizações, mas para contribuir de forma mais ampla para a sustentabilidade da sociedade como um todo. Este conceito foi se fortalecendo a medida que os efeitos negativos da industrialização no meio ambiente como diminuição da camada de ozônio, mudanças climáticas, degradação dos ecossistemas, foram aumentando e impactando as pessoas e os governos (ELMUTI; ABEBE; NICOLOSI, 2005; HALL; DANEKE; LENOX, 2010).

O empreendedorismo sustentável é portanto um tema de pesquisa relativamente novo que nasceu de um esforço para conectar os campos de conhecimento do empreendedorismo e da sustentabilidade, emergindo de estudos sobre negócios, meio ambiente, responsabilidade social (BOSZCZOWSKI; TEIXEIRA, 2012). Ele implica que os recursos renováveis devem ser usados sempre que possível e que os recursos não-renováveis devem ser reduzidos ou reciclados a fim de viabilizar a extensão das gerações que estão por vir. Isto naturalmente traz implicações para que haja uma convergência social, ambiental e econômica (HALL; DANEKE; LENOX, 2010).
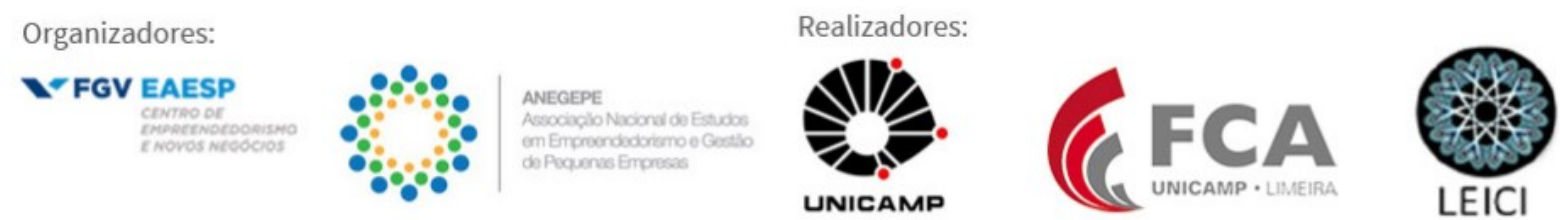
O ecoempreendedorismo ou empreendedorismo verde são uma forma de empreendedorismo sustentável praticada por empreendedores que encontraram novos negócios baseados nos princípios de sustentabilidade (KIRKWOOD; WALTON, 2010; PROCHNOW; VASCONCELOS, 2008; SWAN; MORGAN, 2016).

O conceito de empreendedor verde ou ecoempreendedor (que serão tomados como sinônimos neste estudo) está ligado aos indivíduos que ganham seu sustento através de uma atividade de negócios financeiramente orientado, que fundou ou estabeleceu um empreendimento no nicho verde e que produzem intencionalmente mais do que consomem para gerar lucro com a atividade (WALLEY; TAYLOR, 2002).

De acordo com Schaltegger (2002) o termo ecoempreendedor é a combinação das palavras "eco" que vem de "ecológico" e "empreendedorismo". Para o autor o ecoempreendedorismo é o empreendedorismo visto através das lentes do meio ambiente. Mais tarde ele amplia o conceito e classifica dois tipos de empreendedores: o empreendedor sustentável (possui motivação de resolver problemas sociais e ambientais por meio de um negócio de sucesso) e o empreendedor ambiental (que deseja contribuir para resolver um problema ambiental enquanto gera lucro) (SCHALTEGGER; WAGNER, 2011).

Para fins deste estudo serão enfocados os estudos orientados ao tipo de empreendedores que possuem tanto motivação econômica, ao estabelecer negócios, quanto o desejo de diminuir os problemas no meio ambiente e a degradação ecológica.

\section{O Ecoempreendedor: Motivações e Tipologias}

Conforme já mencionado o ecoempreendedor é a figura chave para promover mudanças no meio ambiente uma vez que seus negócios são construídos levando em consideração a preservação do planeta e seus recursos.

Já as razões para empreender em negócios verdes são variadas. Embora ainda existam poucos estudos ligados ao empreendedorismo verde em relação a farta literatura sobre os motivadores para empreender em geral, observa-se que existe certo consenso entre os pesquisadores, embora as nomenclaturas e propostas de tipologias variem entre eles (KIRKWOOD; WALTON, 2010).

Schaltegger (2002) propôs uma tipologia com cinco tipos de eco empreendedores que são distinguidos em relação ao nível de orientação ambiental da empresa ao impacto que esta tem sobre o mercado. Linnanen (2002) pesquisou os ecoempreendedores e a partir de um estudo multicascos classificando-os em dois critérios: desejo de mudar o mundo e desejo de ganhar dinheiro. A partir dessa classificação criou uma matrix de alto/baixo em relação a combinação das categorias que resultou em quatro tipos de ecoempreendedores: a) Self-employer: empreendedores que desejam ser diferentes do modelo capitalista,são satisfeitos com um nível de fluxo de caixa suficiente para garantir seu padrão de vida. b) Non-profit business: desejam mudar a sociedade, mas não desejam crescer, os limites e semelhanças com uma ONG não são claramente definidos. c) Oportunists: normalmente tem experiência em indústria, expandindo para ecobusiness para criar lucro. Motivados por lucro e não valores. d) Successful idealist: encontram equilibrio entre ganhar dinheiro e fazer o mundo melhor, por possuir forte desejo de mudar o mundo são impulsionados a criar novos mercados e assim constroem um círculo vicioso.
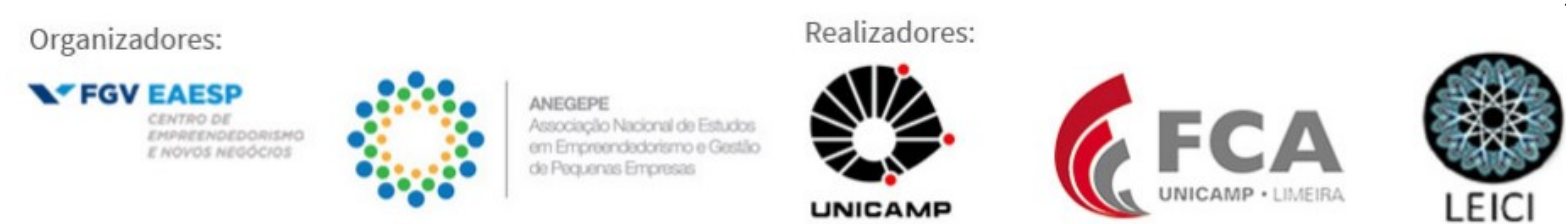
Kirwood \& Walton (2008) em um estudo que visava compreender os motivadores para que eco empreendedores iniciassem negócios apontou cinco grandes motivadores: a) valores verdes: estes empreendedores combinam seus valores com percepções de lacunas no mercado, mantendo uma atividade sustentável; b) ganhar o sustento: para estes empreendedores ganhar o sustento é a motivação principal; c) paixão: além de seus valores verdes alguns empreendedores declaram possuir verdadeira paixão pela área de negócio o que os motivou a seguir com o empreendimento; d)ser seu próprio chefe: esta foi a motivação de outro grupo de empreenderes que haviam ou não trabalhado como empregados no passado; e) percepção de lacuna no mercado - alguns empreendedores entrevistados pelos autores apontaram lacunas percebidas a partir de suas necessidades pessoais e a partir disso iniciaram um negócio para preenche-las. Os autores também apontam que os empreendedores verdes têm motivações similares aos empreendedores em geral mas diferem no que se refere aos valores verdes e na menor motivação financeira.

Swan \& Morgan (2016) mais tarde apontaram que os estudos existentes citam como motivações para ecoempreender a criação de um estilo de vida idealizado, desejo de autonomia no trabalho, a promoção de um meio ambiente sustentável e o incentivo a práticas culturais além do desejo econômico.

O presente estudo utilizará como base a tipologia de Walley \& Taylor (2002) que classifica os empreendedores de acordo com um modelo tipológico em que as categorias não são mutuamente excludentes, isto é, um empreendedor pode, em tese, ser caracterizado em mais de um dos 4 tipos, de acordo com a combinação de seus atributos (WALLEY; TAYLOR, 2002).

De acordo com esses os autores e para fins desta pesquisa será utilizada a definição de negócios verdes como empreendimentos aqueles criados nos princípios da sustentabilidade e o conceito de empreendedor verde como um indivíduo financeiramente orientado que fundou ou estabeleceu um negócio no nicho verde. Assim parte-se do pressuposto que tais empreendedores têm, em alguma escala, objetivos de maximização de lucros. Portanto este modelo de tipologia não abarca o setor sem fins lucrativos, embora atesta-se que muitas vezes o empreendedor verde também tem motivações ético-sociais (SWAN; MORGAN, 2016).

$\mathrm{Na}$ visão de Walley \& Taylor (2002) as variáveis mais importantes para caracterizar os empreendedores verdes são a motivação de mudar as estruturas de sociedade atuais (que vão de leve a forte) e a motivação de empreender (que vai de uma orientação puramente econômica a uma orientação para a sustentabilidade) criando desta forma 4 grandes tipos de empreendedores verdes: a) Innovative Opportunist que é fortemente orientado economicamente e vislumbrou uma oportunidade verde. Este tipo de empreendedor iniciou no nicho por forte motivação estrutural tal como uma nova legislação que o forçou ou levou a criar um produto ou processo com determinada especificação ecológica ou ambiental, b) Visionary Champion que corresponde a um empreendedor envolvido com uma transformação de orientação sustentável. O objetivo dele é mudar o mundo, com uma visão de sustentabilidade futura que visa uma transformação radical nas estruturas vigentes, c)Ethical Maverick que é um tipo de empreendedor verde de leve motivação para mudar as estruturas porém com forte direcionamento sustentável. No geral este tipo de empreendedor teve por influência para montar o negócio a opinião de amigos, de uma rede de relações ou experiências pessoais passadas e mantém o foco do negócio para manter seu estilo de vida, d) Ad Hoc Enviropreneur é o empreendedor acidental, que foi levado a explorar o nicho verde muito mais por motivações
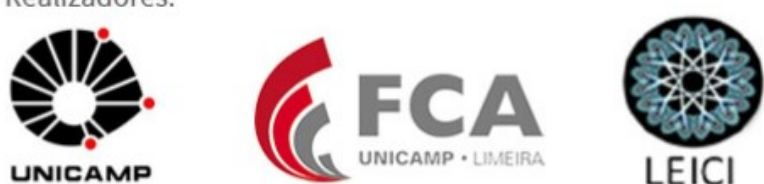
financeiras que por valores pessoais e com pouco ou nenhum desejo de mudar o mundo ou as estruturas vigentes.

É importante salientar que os autores destacam que um modelo de tipologias não deve ser rígido já que é próprio dos empreendedores se reinventarem e reinventarem seus negócios ao longo do tempo, de modo que é possível observar alguma movimentação entre um tipo e outro. Tampouco é o objetivo de um modelo de tipologias enrijecer ou etiquetar a pessoa do empreendedor em um tipo ideal ou outro mas sim servir de ferramenta para a melhor compreensão dos aspectos ligados a motivação destes profissionais (WALLEY; TAYLOR, 2002).

\section{Metodologia}

Esta pesquisa apresenta-se como qualitativa e exploratória. O modelo qualitativo foi escolhido por ser o mais indicado para estudar campos do saber ainda em construção bem como captar de forma aprofundada acerca da natureza do objeto em questão (GODOI; BANDEIRADE-MELO; SILVA, 2006). A pesquisa é exploratória porque permite uma maior familiaridade entre o pesquisador e o tema pesquisado (NEUMAN, 1997). De acordo com Creswell (2010) são típicos da pesquisa qualitativa a coleta de dados no ambiente natural, o pesquisador como coletor dos dados e observador do comportamento dos entrevistados, a utilização de várias fontes de dados como documentos, observações e entrevistas, além é claro, da possibilidade de investigação interpretativa.

A estratégia de pesquisa utilizada foi o estudo de casos múltiplos que seguindo as recomendações de Eisenhardt (1989) foram usadas para dar maior robustez a pesquisa já que permite triangulação de dados entre as entrevistas semi-estruturadas, observação não participante e análise documental. Dessa forma, foi feito um levantamento de pequenos ecoempreendedores que atuam na região metropolitana de Curitiba. Os critérios de seleção foram definidos de acordo com o conceito de ecoempreendedorismo utilizado nesse estudo.

Os empreendedores foram contatados por e-mail e telefone e aceitaram participar da pesquisa. Fizeram parte do estudo cinco micro ou pequenas empresas, do setor de eco turismo, todas localizadas na região metropolitana de Curitiba. As empresas selecionadas foram: um restaurante, um produtor de alimentos orgânicos/atividades de eco turismo, uma pousada ecológica, uma loja de artesanato e uma agência de eco turismo.

Os empreendedores foram entrevistados com base em um roteiro semiestruturado criado pelas autoras com base no modelo de tipologias desenvolvido por Walley \& Taylor (2002) a fim de conhecer o contexto de atuação da empresa, seu histórico e as motivações para empreender na área.

Os relatos da entrevista foram analisados também a partir da observação não participantes e foi realizada análise documental de documentos fornecidos pelos entrevistadores como folders de divulgação e pesquisa na internet a fim de cruzar os dados aumentando a validade interna do estudo com múltiplas fontes de dados.

As entrevistas foram gravadas, transcritas e submetidas à análise de conteúdo numa perspectiva qualitativa de acordo com Bardin (2011) em que os elementos passaram por uma pré-análise de seus conteúdos, a fim de sistematizar as ideias dos entrevistados que ao final puderam ser resumidas nas seguintes categorias de análise: setor de atividade, categoria de
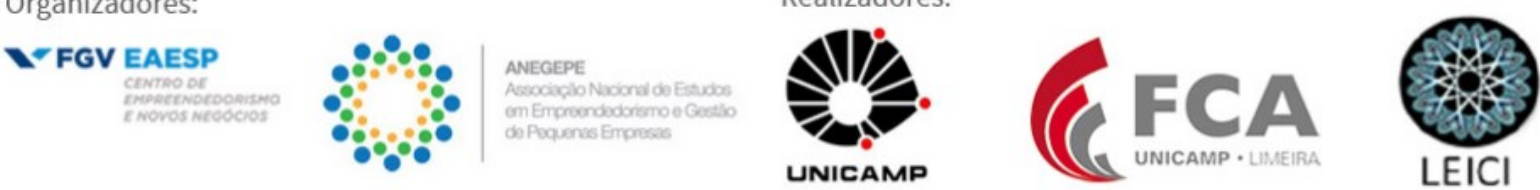
ecosustentabilidade do negócio, regime tributário da empresa, tempo de atuação e motivação principal na criação do negócio.

A seguir será apresentada a descrição dos cinco casos pesquisados. Os casos serão descritos em função das seguintes características de análise: características da empresa, dos entrevistados, motivações para criar o negócio, impacto do negócio na comunidade bem como sua relação com o meio ambiente e percepção de lucros.

\section{Descrição e Análise dos Casos}

A empresa n.1 consiste em um restaurante localizado em uma área rural, fundado e idealizado há 11 anos por dois sócios. Além do restaurante com capacidade para 250 pessoas, o empreendimento conta com vários atrativos de lazer junto a natureza como: trilhas na mata, um centro naturista com tratamentos de saúde, baseados na fitoterapia e hidroterapia, passeios entre a horta e pomar orgânico, lagos para pesca esportiva, interação com os animais da chácara, passeio de barco no lago e cavalgada. Além disso o restaurante construiu um centro de reciclagem que visa a redução dos desperdícios e geração de húmus para suas hortas e pomares. O entrevistado foi o dono e gestor do local, do sexo masculino, casado e com formação em Direito. O estabelecimento possui 3 funcionários além do trabalho do próprio entrevistado que atua na gestão administrativa e atendimento aos clientes. O proprietário atribui o sucesso do restaurante ao "boca a boca" pois os clientes iam recomendando o local para seus conhecidos o que foi ampliando o número de clientes gradativamente. $O$ entrevistado não possuía experiência anterior na função e relata: "aprendemos na prática mesmo, errando e acertando, sempre tentando fazer o nosso melhor" (Entrevistado 1). Em relação ao impacto que o negócio tem na comunidade, ele disse que só contrata mão de obra da região e dá preferência a fornecedores também da região. Os produtos que adquire são em sua maioria da colônia local assim ajuda a comunidade e os produtores locais que são valorizados. Em relação ao meio ambiente ele relata que a preservação da área de $250.000 \mathrm{~m} 2$, sempre esteve entre suas principais preocupações. Desde o início o negócio foi baseado em uma visão ecológica em que os empreendedores buscavam preservar a área verde e oportunizar para as pessoas da cidade a experiência de desfrutar da natureza de forma sustentável, diminuir o estresse do dia a dia e melhorar a conscientização em relação a conservação ambiental. Com o passar do tempo além do restaurante e da área verde foram acrescentados o centro de reciclagem, os passeios a cavalo, a chalana e os tratamentos de saúde alternativos. De acordo com o proprietário a intenção é unir o benefício ecológico com o cultural (casa histórica/culinária típica) através do lazer e turismo. Ao ser questionado em relação a importância do lucro no negócio ele responde que: “ de zero a dez a importância do lucro para mim é dez pois um negócio sem lucro não sobrevive muito tempo, acho que é por isso que nós estamos no mercado há mais de uma década" (Entrevistado $1)$.

A segunda empresa participante do estudo é uma chácara dedicada a produção de alimentos orgânicos certificados fundada e gerenciada por uma família. Além da produção de alimentos, o empreendimento oferece opções de eco turismo como: trilhas para caminhada na mata e passeios de bicicleta, palestras sobre o tema Educação Ambiental e eventos. A fundadora conta que no início, em meados dos anos 2000, a família desejava apenas se mudar para o meio rural
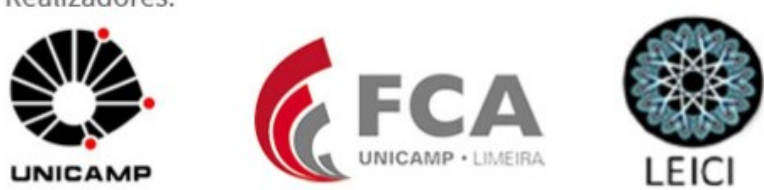
e morar em um local tranquilo e com boa qualidade de vida. Ela era dona de casa e nunca havia empreendido. A agricultura começou inicialmente para consumo próprio, e por causa da preocupação com um consumo saudável, eles começaram a se interessar pelo cultivo orgânico. Aos poucos, amigos, conhecidos e vizinhos mostraram interesse no consumo das verduras e frutas mais saudáveis. A família começou a produzir mais para atender essa demanda. Assim eles investiram na propriedade e se qualificaram para conseguir se certificar. Hoje possuem certificação pelo TECPAR que garante a procedência dos alimentos e já produzem além dos alimentos in natura, geleias, sucos e temperos. Além da produção, contam com serviços de entrega personalizadas que atende a pessoas físicas, restaurantes e supermercados. A empreendedora não tinha experiência anterior no negócio, mas foi se qualificando tecnicamente a medida que o empreendimento foi crescendo. Atualmente além das 4 pessoas da família que trabalham no negócio existem mais 3 funcionários contratados. Sobre a motivação da empreendedora em iniciar o negócio ela coloca que de inicio eles apenas pensavam emter uma vida mais saudável mas que percebeu a oportunidade de negócio e começaram a investir. No que tange a importância do lucro ela pontua como muito importante e atribui nota dez a este aspecto mas também diz que a preservação da natureza é igualmente importante pois sem a mesma não haveria possibilidade de um aproveitamento sustentável.

A terceira empresa é uma pousada ecológica, situada próximo a uma reserva ambiental de Mata Atlântica. Das empresas entrevistadas esta é a que tem o acesso mais difícil pois é feito por estrada de terra. Existe pouquíssimos empreendimentos no local de modo que a pousada fica isolada de outros tipos de comércio. A empresa existe há 18 anos e foi fundada por um casal de empreendedores. A entrevistada foi a fundadora de 47 anos, casada, ensino médio completo que reside no local. Além dela, trabalha na pousada uma outra funcionária. Os empreendedores não tinham experiência anterior na área. Ela conta que foi influenciada por amigos que tinham uma chácara junto a natureza com quem conviviam e o casal começou a sonhar em ter seu próprio espaço. De início, idealizaram apenas um lugar em que eles pudessem estar longe da cidade grande, em harmonia com o meio ambiente. Aos poucos o número de amigos e conhecidos a frequentar o local foi aumentando e veio a ideia de abrir a casa para o público, iniciando assim a pousada. Com o passar dos anos o local foi ampliando, melhorando a estrutura física e atraindo mais visitantes. Neste empreendimento, destaca a entrevistada que a questão da preservação ambiental é essencial. Ao ser perguntada sobre a importância do lucro financeiro com o empreendimento ela diz que é a parte menos importante para ela e atribui nota dois pois durante todos esses anos não houve foco na lucratividade e sim em manter o local funcionando e cumprindo sua missão ecológica.

A quarta empresa é uma loja de artesanato situada em uma região bastante turística, uma colônia de imigrantes na região metropolitana de Curitiba. A empresa existe há 5 anos e foi fundada pela própria empreendedora que tem 58 anos, é casada, formada em Pedagogia e aposentada do setor público. Ela é a única a atender no local mas nos dias de maior movimento conta com a ajuda do marido para fazer o atendimento. A empreeendedora relata que produz as peças, feitas de fibra natural e outros materiais recicláveis, em seu ateliê em casa durante a semana, quando a loja está fechada e atende as centenas de turistas que visitam o local durante os fins de semana e feriados quando a loja está aberta. A entrevistada relata que sempre sonhou em viver de artesanato. Era funcionária pública em Curitiba e após a aposentadoria queria empreender. A empreendedora não tinha experiência anterior nesta atividade, mas a mãe era

Organizadores:

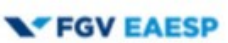

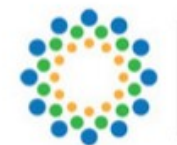

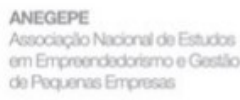
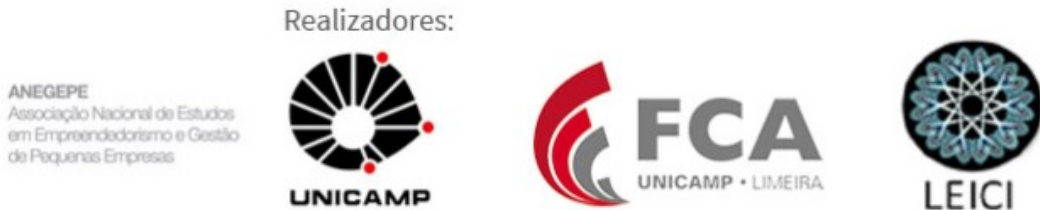
artesã e desde criança ela fazia artesanato. Durante sua carreira como pedagoga a arte era apenas um hobby, mas ela já sonhava em ter uma loja. Outra experiência anterior que a auxiliou muito foi o fato de ter dado muitos cursos de Atendimento ao Cliente durante sua carreira na função pública. Ela acredita que esse conhecimento foi bastante importante e a ajuda hoje. Além disso ela fez muitos cursos no Sebrae para se preparar e se sentir pronta para empreender assim que conseguisse a aposentadoria. Sobre a motivação da empreendedora em iniciar o negócio ela conta que sempre sonhou em ter um negócio próprio, que pudesse ser compatível com um estilo de vida no campo, com uma alimentação mais saudável e junto a natureza. Quando conheceu a região achou o lugar perfeito para realizar este sonho. Ao ser questionada o quanto em uma escala de zero a dez era importante para ela obter lucro no negócio ela pontua com cinco.

A quinta empresa que fez parte do estudo é uma agência de ecoturismo, fundada por duas irmãs que administram o negócio. A entrevistada foi a irmã mais jovem que tem 42 anos, e é casada. Além das duas irmãs sócias trabalham na empresa mais 2 funcionários. A empresa existe há 8 anos e atua como agência de viagens com foco em venda de pacotes de viagens ecológicos nacionais e internacionais. Atende tantos clientes particulares quanto corporativos. A entrevistada explica como surgiu a ideia de empreender: "Surgiu pelo desejo de ter algo próprio e vimos um nicho de mercado a ser explorado - passeios ecológicos". Entretanto, após algum tempo, elas começaram a oferecer também outros tipos de viagens para ampliar o portfólio da empresa. Ela não tinha experiência direta e nem formação voltada para a atividade. De acordo com ela o maior motivador para iniciar o negócio foi o desejo de ter um negócio próprio, de poder fazer os próprios horários e tomar as próprias decisões em relação a seu futuro profissional. Ela coloca que o início do negócio não foi baseado somente na questão ecológica, mas que ambas sócias se preocupam com as questões ambientais e desejam que sua atividade contribua para a preservação do meio ambiente. Ela pontua a importância do lucro no negócio na escala de zero a dez como sendo extremamente importante com nota dez pois a empresa é responsável pelo sustento da família, portanto, a proprietária está sempre se esforçando para aumentar a lucratividade do negócio.

As características das empresas estudadas estão sintetizadas no quadro 1:

Quadro 1 - Características das empresas entrevistadas

\begin{tabular}{|l|l|l|l|l|}
\hline & Setor de atividade & $\begin{array}{l}\text { Número de } \\
\text { empregados }\end{array}$ & $\begin{array}{l}\text { Tempo de } \\
\text { atuação }\end{array}$ & $\begin{array}{l}\text { Categoria de } \\
\text { Empresa }\end{array}$ \\
\hline Caso 1 & Restaurante & 3 & 11 anos & Simples Nacional \\
\hline Caso 2 & $\begin{array}{l}\text { Produção de orgânicos e } \\
\text { atividades de eco turismo }\end{array}$ & 3 & 17 anos & Simples Nacional \\
\hline Caso 3 & Pousada & 1 & 18 anos & MEI \\
\hline Caso 4 & Loja de artesanato & Não possui & 5 anos & MEI \\
\hline Caso 5 & Agência de eco turismo & 2 & 8 anos & Simples Nacional \\
\hline
\end{tabular}

Fonte: elaborado pelas autoras

Observa-se que, com exceção da loja de artesanato que não possui funcionários contratados, as demais empresas possuem dois e três funcionários o que aponta o desenvolvimento e geração de empregos das pequenas empresas na área do turismo. De acordo com Pimentel et al. (2013) desde a regulamentação da Lei Complementar 123/2006 percebe-se um esforço em termos de políticas públicas para o incremento das micro e pequenas empresas, o que vem contribuindo

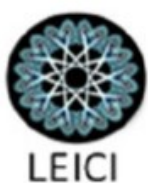


para a formalização do empreendedor. Segundo o autor, este cenário beneficiou as atividades ligadas a cadeia do turismo e suas oportunidades de expansão.

Das empresas participantes do estudo, três encontram-se enquadradas como Simples Nacional ou seja, possuem limites anuais de faturamento de $\mathrm{R} \$ 4,8$ milhões enquanto as empresas enquadradas como Microempreendedor Individual (MEI) possuem limites anuais de R\$ 81 mil (RECEITA FEDERAL, 2017). Somente a pousada e a loja de artesanato estão enquadradas no MEI, de modo que o faturamento das outras 3 empresas entrevistadas é maior. Outro dado que se destaca é o tempo de fundação das empresas. A maioria tem mais de uma década de atuação, e estão em constante crescimento. Este dado encontra consonância na literatura onde vários autores citam que o ecoturismo teve um desenvolvimento rápido na última década refletindo o desejo das pessoas de se manter em contato com a natureza (Orsi et al., 2017; Swan \& Morgan, 2016). Por outro lado os achados contradizem Leite et al. (2017) sobre as microempresas no setor do turismo no Brasil e cita os altos índices deste tipo de negócio.

O progresso dos ecoempreendedores pesquisados pode estar ligado a ações públicas mais especificamente realizadas na região metropolitana de Curitiba, no estado do Paraná, confirme cita o estudo de Silveira (2005). Desde o ano de 1998 foi iniciada a implantação de projetos de turismo em escala local como o chamado "Anel de Turismo" que conectou governo, município e empreendedores locais. Destes, o turismo rural e o ecoturismo são as duas principais modalidades mais incentivadas na região. Esse fator pode ter tido impacto na longevidade das empresas entrevistadas.

Em relação ao perfil dos ecoemprendedores pode ser resumido conforme o quadro 2:

Quadro 2 - Perfil dos Ecoempreendedores

\begin{tabular}{|l|l|l|l|l|}
\hline Entrevistados & Idade & Estado civil & Experiência na atividade & Escolaridade/ Área \\
\hline Caso 1 & 29 anos & Casado & Não possuía & Superior - Direito \\
\hline Caso 2 & 63 anos & Casada & Não possuía & Ensino médio \\
\hline Caso 3 & 47 anos & Casada & Não possuía & Ensino médio \\
\hline Caso 4 & 58 anos & Casada & Não possuía & Superior- Pedagogia \\
\hline Caso 5 & 42 anos & Casada & Não possuía & Superior - Nutrição \\
\hline
\end{tabular}

Fonte: elaborado pelas autoras

Constata-se nesse estudo que nenhum dos entrevistados possuía experiência na área o que está em consonância com um estudo anterior de Teixeira (2012) que pesquisou a criação de novos negócios em turismo em Curitiba-PR e encontrou que a maioria dos negócios estudados iniciou informalmente a partir de empreendedores que não detinham informações aprofundadas do setor.

A idade dos entrevistados é variada e todos são casados. Em relação a escolaridade todos possuem ensino médio completo, sendo que três dos entrevistados possuem graduação em nível superior. Destes, em relação a área de formação observa-se que nenhuma está relacionada a atividade que exercem atualmente.

No que tange o reconhecimento de seu empreendimento como tendo um impacto para o meio ambiente, todos são unânimes em afirmar que a empresa atua de forma positiva para preservar a natureza e utiliza de práticas sustentáveis. Assim, os entrevistados se mostraram ecologicamente conscientes em relação ao papel de suas empresas no meio ambiente, embora, não necessariamente, o eco empreendedor para ser considerado como tal, deve estar imbuído

\section{Organizadores:}

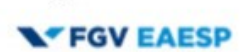

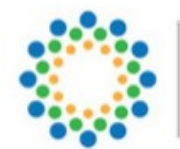
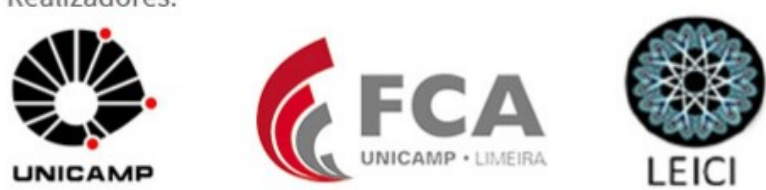
desta consciência (Hoogendoorn, Guerra, \& van der Zwan, 2015; Fonseca, Silva, Santos \& Leite, 2015).

Com o objetivo de classificar os empreendedores deste estudo no modelo de tipologias de Walley \& Taylor (2002), foi extraído da fala dos entrevistados sua principal motivação para empreender e comparado a descrição de categorias dos autores. Os achados demonstram que a três dos entrevistados corresponde ao tipo Ethical Maverick que possui forte direcionamento para a sustentabilidade e baixa motivação para mudar as estruturas. No caso da loja de artesanato pode-se enquadra-la em duas categorias já que além de possuir as características do Ethical Maverick ela também corresponde as características do Visionary Champion, isto é, além de utilizar o negócio para manter seu estilo de vida, a empreendedora deseja mudar as estruturas através da conscientização das pessoas.

Por outro lado, a agência de turismo ajusta-se a definição de Ad Hoc Enviropreneur uma vez que entrou no negócio quase por acidente, ao perceber uma oportunidade não explorada por outras agencias e que estava em amplo crescimento na época da fundação da empresa.

Um resumo das tipologias com as motivações principais dos empreendedores encontra-se no quadro 2:

Quadro 3- Tipologias de motivações de ecoempreendedores

\begin{tabular}{|l|l|l|l|}
\hline & Empresa & Motivação principal & $\begin{array}{l}\text { Tipologia do } \\
\text { Empreendedor }\end{array}$ \\
\hline Caso 1 & Restaurante & $\begin{array}{l}\text { Preservar a área verde e oportunizar para } \\
\text { as pessoas da cidade a experiência de } \\
\text { desfrutar da natureza, longe do estresse da } \\
\text { cidade grande }\end{array}$ & Ethical Maverick \\
\hline Caso 2 & $\begin{array}{l}\text { Chácara de } \\
\text { Orgânicos e } \\
\text { Ecoturismo }\end{array}$ & $\begin{array}{l}\text { Ter um estilo de vida mais saudável, no } \\
\text { início não tinham intenção de montar um } \\
\text { negócio mas vislumbraram a oportunidade } \\
\text { e investiram. }\end{array}$ & Ethical Maverick \\
\hline Caso 3 & Pousada & $\begin{array}{l}\text { De início, idealizaram apenas um lugar em } \\
\text { que eles pudessem estar longe da cidade } \\
\text { grande, em harmonia com o meio } \\
\text { ambiente, foram influenciados por amigos. }\end{array}$ & Ethical Maverick \\
\hline Caso 4 & $\begin{array}{l}\text { Loja de } \\
\text { artesanato }\end{array}$ & $\begin{array}{l}\text { Acredita que seu trabalho fazer parte de } \\
\text { uma missão de vida que inclui o incentivo } \\
\text { a preservação da natureza além de manter } \\
\text { seu estilo de vida. }\end{array}$ & $\begin{array}{l}\text { Visionary Champion e } \\
\text { Ethical Maverick }\end{array}$ \\
\hline Caso 5 & $\begin{array}{l}\text { Agência de } \\
\text { eco turismo }\end{array}$ & $\begin{array}{l}\text { Desejo de ter um negócio próprio, } \\
\text { vislumbraram um nicho de mercado } \\
\text { desatendido para ser explorado. }\end{array}$ & Ad Hoc Enviropreneur \\
\hline
\end{tabular}

Fonte: elaborado pelas autoras

Em relação a importância atribuída a lucratividade no negócio, observou-se que apenas a dona da pousada não considera o lucro como fundamental para a sobrevivência do negócio. Em seu discurso ela pontua que nunca teve a intenção de acumular capital através do negócio, ao contrário, desde o início a ideia foi viver com simplicidade, junto a natureza e que o lucro gerado sempre foi reinvestido no negócio, a fim de preservar a propriedade e seu estilo de vida.

Constata-se que no restaurante, na chácara de orgânicos/ecoturismo e na agencia de ecoturismo a questão da lucratividade é muito importante, tendo recebido peso máximo e está
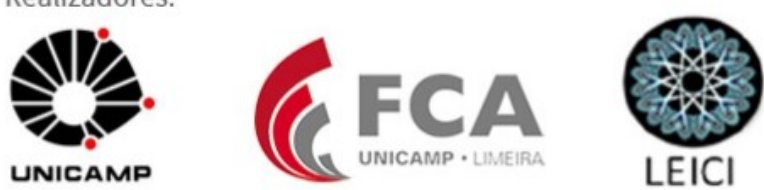
inclusive relacionada ao sustento dos empreendedores e de suas famílias. Já a loja de artesanato não é a única fonte de renda da empreendedora, que é aposentada de outra função, e talvez por esta razão ela tenha atribuído uma nota média de cinco. Em seu discurso fíca claro que a existência do negócio está mais relacionada a sua satisfação com a atividade e valores pessoais que ela pratica como uma missão de vida.

De forma geral independente da nota atribuída a lucratividade, todos os entrevistados mostraram-se com alto nível de consciência em relação ao impacto de seus empreendimentos no meio ambiente. Os achados deste estudo corroboram com os de Allen \& Malin (2008) que estudaram casos de pequenos empreendedores verdes e Silajdzic, Kurtagic, \& Vucjakjak (2015) que destacaram em sua pesquisa a forte conexão entre os eco empreendedores e seus valores pessoais. A questão dos valores verdes fica bastante evidente nos discursos e também na origem dos empreendimentos conforme relatado pelos entrevistados e sugerido também em diversos estudos no tema (GIBBS, 2009; KIRKWOOD; WALTON, 2010; SCHALTEGGER, 2002; SWAN; MORGAN, 2016).

\section{Conclusão:}

Os achados desta pesquisa demonstram o esforço dos empreendedores em expandir a preocupação ecológica de seu negócio e englobar outras formas de diminuir o impacto negativo de sua atuação através da preocupação com o consumo de agua responsável, reciclagem do lixo, não utilização de agrotóxicos e busca de utilização de fontes de energia renovável. Observa-se também que os achados desta pesquisa estão em consonância com os achados de outros autores que estudaram os ecoempreendedores, seu perfil e motivação (ISAAK, 1998; KIRKWOOD; WALTON, 2010; LINNANEN, 2002; WALLEY; TAYLOR, 2002).

Os maiores motivadores encontrados foram econômicos e ao mesmo tempo contribuir para a preservação da natureza. Os ganhos econômicos possuem importância, conforme pontuado pelos entrevistados, entretanto as ações ecológicas são parte integrante da lógica de seus negócios conforme achados de outros pesquisadores como Hockerts \& Wüstenhagen (2010), Asadi \& Kohan (2011), Sidali, Kastenholz, \& Bianchi (2015).

Embora os achados deste estudo estejam limitados a cinco casos de eco empreendedores e não possam ser generalizados, suas experiências comuns acrescentam valor para a compreensão de seus comportamentos, motivações e pode prover direção a futuros estudos. Sugere-se que futuros estudos abordem métodos quantitativos para acessar as motivações dos ecoempreendedores e também possa comparar os achados dessa pesquisa com ecoempreendedores de outras regiões no Brasil.

\section{Referências:}

ALLEN, J. C.; MALIN, S. Green Entrepreneurship: A Method for Managing Natural Resources? Society \& Natural Resources, v. 21, n. 9, p. 828-844, 2008.

ANUP, K. C.; RIJAL, K.; SAPKOTA, R. P. Role of ecotourism in environmental conservation and socioeconomic development in Annapurna conservation area, Nepal. International Journal of Sustainable Development and World Ecology, v. 22, n. 3, p. 251-258, 2015.
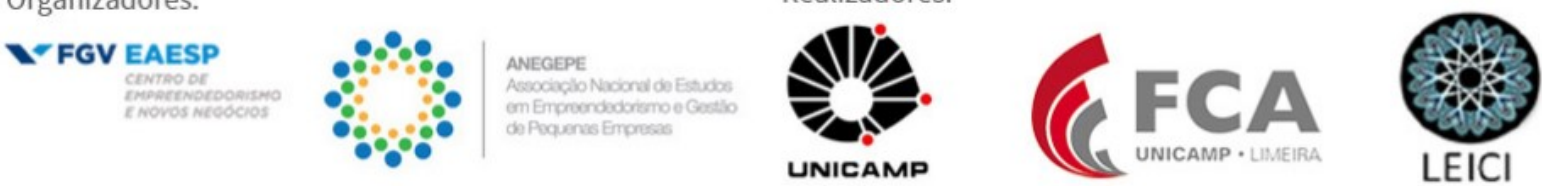
ASADI, A.; KOHAN, M. F. Z. The role of Entrepreneurship on Ecotourism development. Sociality and Economics Development, v. 10, p. 38-42, 2011.

BARDIN, L. Análise de Conteúdo. São Paulo: Edições 70, 2011.

BORGES, C; FERREIRA, V.; NAJBERG, E.; TETE, M.. Empreendedorismo sustentável: proposição de uma tipologia e sugestões de pesquisa. Revista de Empreendedorismo e Gestão de Pequenas Empresas, v. 2, n. 1, p. 77-100, 2013.

BOSZCZOWSKI, A. K.; TEIXEIRA, R. M. O empreendedorismo sustentável e o processo empreendedor: em busca de oportunidades de novos negócios como solução para problemas sociais e ambientais. Economia \& Gestão, v. 12, n. 29, p. 141-168, 2012.

BUDEANU, A. et al. Sustainable tourism, progress, challenges and opportunities: an introduction. Journal of Cleaner Production, v. 111, p. 285-294, 2016.

CRESWELL, J. W. Projeto de Pesquisa: Métodos Qualitativo, Quantitativo e Misto. Porto Alegre: Artmed, 2010.

EISENHARDT, K. M. Building Theories from Case Study Research. Academy of Management Review, 1989.

ELMUTI, D.; ABEBE, M.; NICOLOSI, M. An overview of strategic alliances between universities and corporations. Journal of Workplace Learning, 2005.

FONSECA, S. M.; SILVA, A. P.; SANTOS, D. C. L.P.; LEITE, E. F. Ecoempreendedorismo E Competências Empreendedoras: O Caso Ecoempreendedor Transformador De Resíduo Em Riqueza. Holos, v. 2, p. 183, 2015.

GIBBS, D. Sustainability Entrepreneurs, Ecopreneurs and the Development of a Sustainable Economy. Greener Management International, v. 55, p. 63-79, 2009.

GODOI, C. K.; BANDEIRA-DE-MELO, R.; SILVA, A. B. Da. Pesquisa qualitativa em estudos organizacionais: Paradigmas, Estratégias e Métodos.São Paulo: Saraiva, 2006.

HALL, J. K.; DANEKE, G. A.; LENOX, M. J. Sustainable development and entrepreneurship: Past contributions and future directions. Journal of Business Venturing, v. 25, n. 5, p. 439448, 2010.

HOCKERTS, K.; WÜSTENHAGEN, R. Greening Goliaths versus emerging Davids Theorizing about the role of incumbents and new entrants in sustainable entrepreneurship. Journal of Business Venturing, v. 25, n. 5, p. 481-492, 2010.

HOOGENDOORN, B.; GUERRA, D.; VAN DER ZWAN, P. What drives environmental practices of SMEs? Small Business Economics, v. 44, n. 4, p. 759-781, 2015.

ISAAK, R. Green Logic: Ecopreneurship, Theory and Ethics. Sheffield: Greenleaf Publishing, 1998.

ISAAK, R. The Making of the Ecopreneur. Green Management International, v. 38, p. 8191, 2002.

KIRKWOOD, J.; WALTON, S. What motivates ecopreneurs to start businesses? International

\section{Organizadores:}

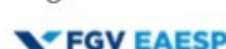

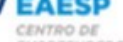

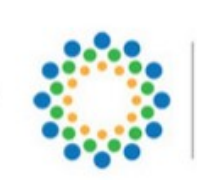

ANEGEPE

=

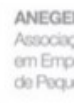

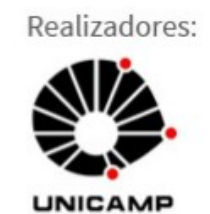


Journal of Entrepreneurial Behavior \& Research, v. 16, n. 3, p. 204-228, 2010.

KOE, W. L.; MAJID, I. A. Socio-Cultural Factors and Intention towards Sustainable Entrepreneurship. Eurasian Journal of Business and Economics, v. 7, n. 13, p. 145-156, 2014.

LEITE, D. B. et al. O ambiente de gestão de MPEs do setor de turismo no Brasil : uma revisão sistemática The management environment at MPEs in the tourism sector at Brazil : a systematic review. Revista Brasileira de Ecoturismo, v. 10, n. 1, p. 157-170, 2017.

LINNANEN, L. An Insider's Experiences with Environmental Entrepreneurship. Greener Management International, v. 38, n. 38, p. 71-80, 2002.

MIESZAJKINA, E. Ecological Entrepreneurship and Sustainable Development. Problems of Sustainable Development, v. 12, n. 1, p. 163-171, 2016.

NEUMAN, W. . Social Reseach Methods. 3. ed. [s.1: s.n.].

ORSI, M. et al. Análise comparativa do turismo sustentável e turismo responsável: semelhanças e diferenças nos destinos turísticos do Brasil. Caderno de Estudos e Pesquisas do Turismo, v. 6, n. 9, p. 39-56, 2017.

PARRISH, B. Sustainability-driven entrepreneurship: Principles of organization design. Journal of Business Venturing, v. 25, n. 5, p. 510-523, 2010.

PASTAKIA, A. Grassroots ecopreneurs: change agents. Journal of Organizational Change Management Grassroots, v. 11, n. 2, p. 157-173, 1998.

PIMENTEL, A. et al. Empreendedorismo e formalização de atividades de turismo em ambientes naturais. Revista Acadêmica Observatório de Inovação do Turismo, v. VII, n. 4, p. 29, 2013.

PROCHNOW, W. E.; VASCONCELOS, E. C. DE. O estado-da-arte das ações para certifi cação em ecoturismo. Caderno Virtual de Turismo, v. 8, n. 3, p. 29-40, 2008.

RECEITA FEDERAL. Acesso em 20 de dezembro de 2017. http://www8.receita.fazenda.gov.br/SimplesNacional/

SCHALTEGGER, S. A Framework for Ecopreneurship. Green Management International, v. 38, n. Summer, p. 45-59, 2002.

SCHALTEGGER, S.; WAGNER, M. Sustainable Entrepeneurship and Sustainability Innovation: Categories and Interactions. Business Strategy and Environment, v. 20, n. 4, p. 222-237, 2011.

SHEPHERD, D. A.; PATZELT, H. E T \& P The New Field of Entrepreneurship : Sustained " With “What Is to Be Developed ”. Entre, v. 35, n. 1, p. 137-163, 2011.

SILAJDZIC, I.; KURTAGIC, S. M.; VUCJAKJAK, B. Green entrepreneurship in transition economies: A case study of Bosnia and Herzegovina. Journal of Cleaner Production, v. 88, p. 376-384, 2015.

SILVEIRA, M. A. T. Turismo e estratégias de desenvolvimento local. Interações, v. 7, n. 11,
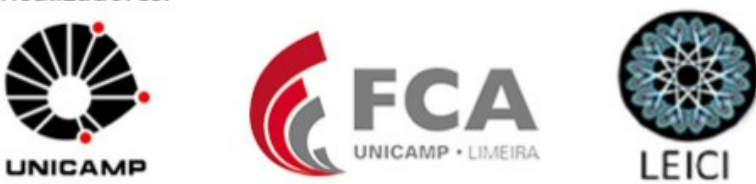
p. 129-140, 2005.

SWAN, C. D.; MORGAN, D. Who wants to be an eco-entrepreneur? Identifying entrepreneurial types and practices in ecotourism businesses. International Journal of Entrepreneurship and Innovation, v. 17, n. 2, p. 120-132, 2016.

TEIXEIRA, R. M. O Processo de Criação de Novos Negócios em Turismo : estudo de casos múltiplos em agências de viagens em Curitiba , Paraná. v. 23, p. 464-483, 2012.

THOMPSON, J. L. The world of the entrepreneur: a new perspective. Journal of Workplace Learning, v. 11, n. 6, p. 209-224, 1999.

TILLEY, F.; YOUNG, W. Sustainability Entrepreneurs - Could they be the TrueWealth Generators of the Future? Greener Management International, v. 55, p. 79-92, 2009.

WALLEY, E. E. L.; TAYLOR, D. W. D. Opportunists, Champions, Mavericks . . ? Green Management International, v. 38, p. 31-43, 2002.

YORK, J.; VENKATARAMAN, S. The entrepreneur-environment nexus: Uncertainty, innovation, and allocation. Journal of Business Venturing, v. 25, n. 5, p. 449-463, 2010. 